\title{
Esferas públicas em movimento
}

\author{
Public Spheres in Motion
}

\section{Esferas públicas en movimento}

\section{Entrevista}

Pablo Ortellado

\section{Entrevistadores}

\section{Luiz Alberto de Farias}

- Livre docente em Opinião Pública e doutor em Comunicação e Cultura pela Universidade de São Paulo (USP).

- Professor associado da Escola de Comunicações e Artes (ECA) da USP.

- Professor titular da Universidade Metodista de São Paulo (Umesp).

- E-mail: Lafarias@usp.br

\section{(9) Daniel Reis}

- Doutor e mestre em Comunicação pela Universidade Federal de Minas Gerais (UFMG).

- Professor da UFMG.

- E-mail: daniel.rs@hotmail.com.br

\section{Valéria de Siqueira Castro Lopes}

- Doutora e mestra em Ciências da Comunicação pela USP.

- Professora doutora da Escola de Comunicações e Artes (ECA) da USP.

- Professora doutora da Faculdade Cásper Líbero.

- E-mail: valeriacastro@usp.br

(9) Camila Paschoal Bezerra

- Mestranda em Ciências da Comunicação na USP.

- E-mail: camilapbezerra@gmail.com

Transcrição

\section{Gabriel Cordeiro}

- Bacharel em Comunicação Social/Relações Públicas pela USP.

- E-mail: gabriel.augusto.silva@usp.br 


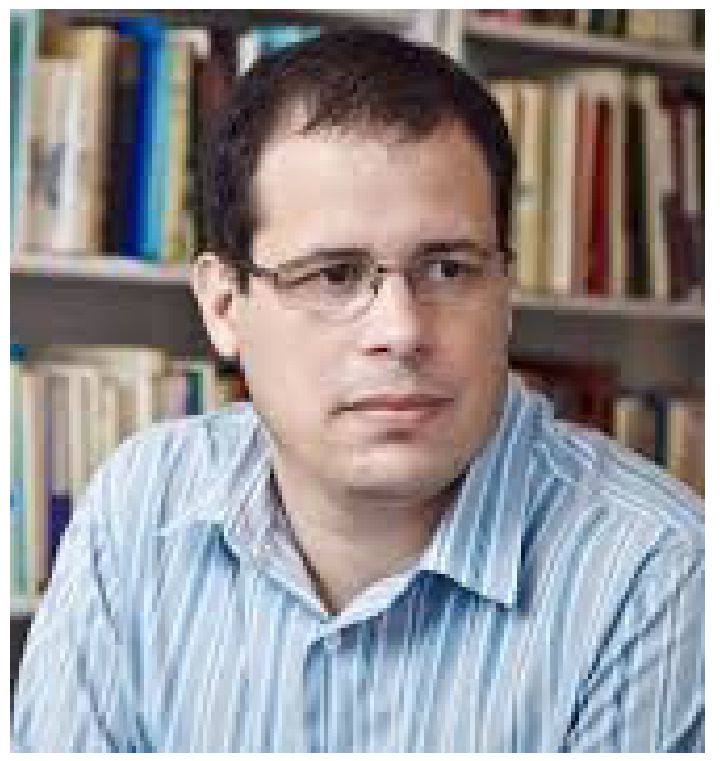

\section{Pablo Ortellado}

- Doutor e bacharel em Filosofia pela USP, com estudos pósdoutorais pelo Centro Brasileiro de Análise e Planejamento (Cebrap Brasil).

- Professor doutor do curso de Gestão de Políticas Públicas da USP.

- Orientador no programa de pós-graduação em Estudos Culturais da USP.

- Coordenador do Grupo de Pesquisa em Políticas Públicas para o Acesso à Informação (GPOPAI).

- Atualmente, desenvolve pesquisa sobre privacidade, políticas culturais e movimentos sociais. 
$\mathrm{P}$ andemia. Insegurança. Redes sociais. Desinformação. Esse cenário bastante incerto tem sido o palco para o estabelecimento das relações entre o concreto e o simbólico na vida das pessoas. Movimentos digitais ganham força na construção de sentido para inúmeros grupos e passam a representar universos nas vidas individuais e coletivas, chamando todos para o debate sobre questões essenciais como igualdade, diversidade e antirracismo, por exemplo, ou ainda sobre temas de desagregação, como negacionismo, discurso de ódio etc. Grandes e complexas teias se formam, trazendo à agenda pública assuntos que, muitas vezes, são revestidos de significativa desinformação, instaurando medo e incerteza.

Diante desse emaranhado de significados fluidos que assolam os processos comunicacionais, a Organicom conversou com o filósofo, professor da Universidade de São Paulo e articulista da Folha de São Paulo Pablo Ortellado sobre os movimentos que impactam a nossa sociedade, as influências de novas forças, como o populismo, e o comportamento das pessoas frente à participação política.

Em plena quarentena, a entrevista se deu por meio do espaço das redes sociais digitais, ambiente que tem tanto a oferecer para o desenvolvimento da sociedade, permitindo aproximação e ampliação do debate democrático, mas que muitas vezes também serve como plataforma para distanciar pessoas e gerar discursos de intolerância.

Falamos sobre o projeto de lei para gerenciar a emissão de falsas informações, crescimento do populismo no Brasil e no mundo, redes sociais - entendidas por muitos como espaço de liberdade de expressão-sendo gerenciadas por empresas com claros interesses de lucro e monetização e influência das tecnologias em eleições. Uma conversa produtiva e que certamente não acaba por aqui, pois o tema é amplo e com novidades a cada dia.

0 professor Ortellado nos mostrou um interessante olhar sobre a desconstrução das teorias conspiratórias que atribuem todo o poder de manipulação somente a um lado da moeda. A partir da entrevista, poderemos ficar ainda mais atentos aos movimentos que ocorrem de todos os lados, nem sempre com a mesma energia ou o mesmo poder, mas gerando benefícios à sociedade, bem como enormes estragos e distorções.

ORGANICOM - Ao longo da história, vários conceitos foram cunhados sobre a opinião pública: como você a definiria?

ORTELLADO - No trabalho que realizo com meu grupo de pesquisa Políticas Públicas para o Acesso à Informação, tem-se evitado o conceito de opinião pública porque ele tende à formação de uma espécie de consenso nacional, quando nosso objeto pede para encontrarmos a estrutura do debate. Por isso, temos trabalhado mais com o conceito de esfera pública, no sentido frankfurtiano: espaço de discussão de assuntos políticos fora do Estado.

ORGANICOM - Alguns autores chegam a dizer que não existe opinião pública, pois prevalece o conceito de redes. As redes sociais digitais conseguem dar conta do papel da formação da opinião pública?

ORTELLADO - Temos observado uma espécie de hipermobilização da sociedade por um lado e, por outro, a presença e o uso crescente de mídias sociais têm feito com que essa esfera pública e a mobilização política se alarguem, mas não exatamente com os efeitos que se esperavam antigamente. Tradicionalmente se via a esfera pública como uma espécie de contraponto ao poder político do Estado, um lugar em que a sociedade civil se organizava e discutia assuntos políticos fora do Estado para 
fazer uma espécie de contraponto, controle, um escrutínio da ação do Estado fora do Estado. Fora da máquina dos militantes político-partidários e da máquina burocrática. Era a sociedade vigiando, controlando, se antepondo ao Estado.

O que aconteceu com o processo da polarização política é exatamente o contrário: são as forças políticas que estão no Estado ou que estão disputando o Estado, se organizando de uma maneira muito alinhada. É difícil saber o que vem antes ou o que vem depois, porque vão se estruturando de uma maneira semelhante. As forças políticas que estão no parlamento, que disputam o poder político do Estado, passam a ter um espelhamento na sociedade civil, que está engordada, alargada, altamente mobilizada e que age de uma maneira semelhante a uma força política no sentido de que atua de maneira irrefletida, orientada para 0 confronto com o adversário político. Isso gera essa espécie de intolerância política, que caracteriza a polarização política em que, em tese, se está combatendo em torno de um ideal, mas na verdade o combate é contra um adversário.

Se formos aos trabalhos originais de Habermas, nos anos 1960, isso não era o que se esperava da esfera pública, que seria esse espaço de discussão. Originalmente, na esfera pública burguesa os homens sensatos, liberais, proprietários se organizavam e discutiam os assuntos do Estado e se antepunham ao poder político. 0 que está acontecendo é o contrário: são militantes políticos, uma espécie de "militantização" da sociedade, o que está gerando comportamentos muito irrefletidos e intolerantes, cuja exacerbação e limite é a violência política. Por isso, parece muito preocupante.

Então, basicamente, o que me parece mais importante do que pensar em uma opinião pública como uma organização da opinião no seio da sociedade civil é pensar como se estrutura o debate na sociedade civil e como se estrutura o debate nessas duas dimensões: nessa nova esfera pública digital - que são as mídias sociais - e os processos de mobilização que estão exacerbados. Temos feito pesquisas de opinião para medir a mobilização política e temos visto na cidade de São Paulo que $30 \%$ dos paulistanos [estão] participando de manifestações políticas (pré-pandemia). Quando fazemos isso no âmbito nacional, são 17\% ou 18\% dos brasileiros participando no último ano de mobilizações políticas. Isso é um nível altíssimo. Então temos uma parcela grande dos brasileiros discutindo assuntos políticos nas mídias sociais e, dependendo de como se meça, conseguese chegar a algo próximo a 50\% dos brasileiros vendo frequentemente notícias políticas nas mídias sociais, e, desses, um terço [de] brasileiros veem assuntos políticos, mobilizam-se e vão às ruas, em um passo de compromisso político ainda mais forte do que apenas ver os assuntos políticos. Temos uma esfera pública intensificada e que assumiu um caráter militante.

ORGANICOM - A sociedadeé cada dia mais conectada a dispositivos, mas talvez menos conectada ao mundo real? A tecnologia é a propulsora da democracia ou ela catapulta os movimentos populistas? Como enxerga o papel da tecnologia nos rumos da sociedade?

ORTELLADO - Se nós acompanharmos o debate sobre o impacto da tecnologia, o debate que veio a partir da privatização da internet - que acontece em 1995, pois antes era uma rede universitária e, a partir de então, empresas passaram a vender acesso à internet - e o [fato de que o] público que estava fora dessa rede, que não era universitário, passou a ter acesso a ela, pode-se entender que as transformações começam a vir a partir daí. Pelo menos as transformações para além do âmbito universitário. Nesses primeiros anos o que se viu foi um discurso tecno-utópico, de que a tecnologia, que a internet - pelo seu caráter de não ser um meio de comunicação unidirecional, por ser bidirecional, participativo, tendo protocolos abertos, internacional, distribuído - criaria um espaço de comunicação descentralizado, sem possibilidade de controle, de censura, e pela própria natureza da tecnologia fomentaria a liberdade de expressão, a auto-organização política, o acesso ao conhecimento e que as leis que restringiam a liberdade de expressão, que restringiam 0 acesso ao conhecimento por meio de direitos autorais, nada disso se aplicaria ao ambiente digital por sua natureza internacional, descentralizada e participativa. 
Esse discurso, muito característico do final dos anos 1990, atravessou a primeira década dos anos 2000. Tem até uma espécie de apoteose, a chamada doutrina Google, a ideia de que a gente teria as revoluções do Twitter, as revoluções do Facebook, como teve nos protestos de 2009, no Irã, ou o ciclo de protestos de 2011 a 2014, com a Primavera Árabe, o Occupy Wall Street, o 15M na Espanha, os protestos de julho de 2013, no Brasil. Com essa ideia de que as novas tecnologias, por sua própria natureza, por sua própria forma, seriam uma força propulsora e libertária que iria transformar a sociedade desde baixo.

Essas ilusões caíram completamente na segunda década do século XXI, quando os desdobramentos desses processos se mostraram ruins. De certa maneira era verdade aquela intuição de que essas ferramentas empoderavam certos atores: elas facilitavam a mobilização social e davam poder a novos atores. Mas quem mais se beneficiou disso não foram os movimentos. É verdade que tivemos um ciclo que Paolo Gerbaudo chamou de anarcopopulista, que é justamente o ciclo que vai tipicamente de 2009 a 2014, com força entre 2011 e 2013, no qual a sociedade civil se empoderou e construiu uma espécie de mobilização permanente, duradoura e forte contra o Estado, por isso anarcopopulismo. Anarco porque era antiestatal, antirrepresentação - tem o grito do 15M "não me representa" e que foi incorporado ao Occupy Wall Street.

Tem esse elemento anárquico, de antirrepresentação política e tem um elemento populista, porque ao contrário dos movimentos sociais característicos do ciclo anterior ao movimento de globalização, ele não se identificava como esquerda. Era uma espécie de movimento de autoidentificação: nós, o povo, contra uma elite corrupta, aquela elite que estava nos países que sofreram a influência da Primavera Árabe, tipicamente, como Mubárak e outras lideranças na Síria, norte da África, toda a região do Magreb e a mesma coisa com as elites econômicas de Wall Street. E mesmo aqui com as elites brasileiras que foram antagonizadas pelo movimento de junho de 2013. Tinham um lado do componente populista no sentido técnico do termo, movimentos políticos que buscam representar o povo em uma dinâmica antagônica "povo versus elites", mas também com a ideia de não só estabelecer um poder político, mas de rejeitar o poder político, de rejeitar a representação.

Esse momento falhou. Esse projeto falhou. A Primavera Árabe foi um fracasso, deixou um rastro de destruição, sobretudo no Egito e na Síria. No 15M o sucesso foi moderado. Houve a criação de um partido político, mas logo houve uma espécie de contraponto na direita e não deixou grandes frutos. Ou pelo menos frutos duradouros nos Estados Unidos e no Brasil. Quem se aproveitou dessa vaga, que podemos ver no Brexit, nos governos Trump e Bolsonaro são forças políticas populistas, mas não anarcopopulistas. São forças políticas populistas de direita, que buscam lutar contra o velho establishment político, mas para instaurar uma nova ordem conservadora. Na verdade, do ponto de vista de transformação política o produto mais assustadoramente duradouro desse processo foram os governos populistas de direita, fazendo uma espécie de inversão de expectativas desse processo que começou em meados dos anos 1990, e no qual nós víamos a tecnologia como portadora da liberdade.

ORGANICOM - Nos últimos anos foram feitas diversas denúncias sobre compra de dados, controle de distribuição de informação, presença maciça de robôs e ciborgues na política. Isso veio em paralelo a um crescimento de movimentos de ultradireita, por exemplo. Acredita que esses elementos estão necessariamente conectados ou que possam ser processos paralelos e independentes?

ORTELLADO - Eu sou um pouco hesitante, mais que hesitante, sou um tanto cético sobre essas explicações que supervalorizam o papel da manipulação tecnológica na ascensão da extrema direita, porque os papéis se misturaram a algumas coisas que tem promovido essa ideia. Primeiramente, existe uma certa incapacidade de a esquerda olhar para os seus erros e para a sua capacidade de oferecer soluções, o que a direita, sobretudo a extrema direita, tem feito, e a esquerda, não. Ao invés de reconhecer que tem falhado, que não tem oferecido soluções, prefere-se atribuir essa vitória a uma espécie de superpoder tecnológico que a direita teria e não estaria ao alcance da esquerda. A isso se soma, por exemplo, no caso da Cambridge Analytica, o discurso da própria empresa, que vende serviços e se vendeu como sendo a responsável pela vitória do Trump. 
No discurso empresarial, de venda de seus próprios serviços, ela disse que Trump era um candidato inviável, com pouca chance de sucesso e ela, por meio de uma grande capacidade tecnológica de intervir no debate, fazendo uma espécie de microtarget orientado para os tipos psicológicos, tentando fazer guerra cultural, explorando as vulnerabilidades desses perfis psicológicos a partir dos dados que tinha, é que teria feito diferença na campanha de Trump.

Mas quando vamos olhar para as pessoas que estudam marketing político e as dinâmicas das mídias sociais, há muito ceticismo com relação a essa alegação da própria empresa sobre [a ideia de que] o modelo baseado em tipos psicológicos é eficaz e que isso foi o fator decisivo na vitória de Trump. Isso é um discurso da empresa. Essas duas coisas se somaram: de um lado o interesse da esquerda de não reconhecer as suas deficiências, e de outro a propaganda da empresa superdimensionando as suas capacidades para fins de oferecer mais serviços. Isso se somou.

Olhando objetivamente, de fato o presidente Bolsonaro tem uma estratégia de robôs no Twitter robusta. Ele sabe explorar muito bem os grupos de WhatsApp, mas nada disso é uma tecnologia ou técnicas de propaganda que outras forças políticas desconheçam. Talvez algumas dessas forças não estejam dispostas a jogar tão sujo quanto ele joga, mas todo mundo sabe operar e, em alguma medida, todo mundo também faz. Há outras forças políticas que têm uma estrutura de campanha por WhatsApp e, no caso do Twitter, em que há exércitos de robôs, existem outros grupos que têm exércitos equivalentes. Não deixam isso permanentemente ligado, mas usam. Eu não acredito que exista uma desproporção no conhecimento, na capacidade de uso de novas tecnologias, novos métodos, novas técnicas por parte da extrema direita que outras forças políticas não tenham.

ORGANICOM - Expressões comofake news e pós-verdade passaram a fazer parte da guerra de narrativas em todos os países. Como entende a reação do cidadão comum a esses fenômenos e a influência nos processos eleitorais - influenciaram/influenciarão?

ORTELLADO - As informações falsas influenciaram o processo eleitoral? Essa é uma pergunta muito difícil de responder, pois não conseguimos saber como teria sido um processo eleitoral em que essas informações falsas não tivessem circulado. Não se consegue isolar esse fator para ver qual teria sido o efeito. Mas o fato de não podermos responder a essa pergunta não significa que não se entendam pedaços do problema. Sabemos, por exemplo, que determinadas convicções estão associadas a crenças em determinadas informações falsas, e que quanto mais as pessoas acreditam em um determinado ponto de vista, mais suscetíveis elas são a aceitar informações falsas. Há muita pesquisa empírica mostrando essa correlação.

Mas essa correlação não é causalidade. Não se sabe se as pessoas aceitaram determinada posição política porque informações falsas as conduziram a tomar essa posição, ou se o fato de terem essa posição antes as tornam mais suscetíveis a acreditar em informações falsas. É muito difícil determinar a ordem das coisas, mas se consegue estabelecer a correlação por meio do poder de pesquisa.

Tudo, ou um pedaço disso, tem a ver com um fenômeno, o viés de confirmação, que é a disposição psicológica em aceitar muito acriticamente informações que corroboram com convicções que já se tem e, como contraponto, rechaçar, de maneira muito dura, informações que desafiam essas convicções. Como o processo de polarização tornou essas convicções muito arraigadas, muito fortes, o viés de confirmação tem atuado, tem sido explorado por esses sites e produtores de desinformação que alimentam essas convicções com informações.

Basicamente, o que se chamava antigamente de sites de notícias falsas, que é esse ecossistema de produção de informação, consiste em pegar o noticiário do dia, [e] adaptar esse noticiário do dia a determinadas perspectivas políticas, martelando os fatos nas interpretações, distorcendo na tentativa de encaixar os fatos nas interpretações, tirando de contexto, eventualmente inventando, aniquilando os fatos, omitindo. E essa informação distorcida aproveita a convicção que as pessoas já têm pelo 
processo de polarização, em que elas estão apaixonadas por suas convicções, e faz com que aceitem muito acriticamente essas informações mentirosas, porque se contrariassem as suas convicções elas rejeitaram de imediato.

Se, por um lado, o viés de confirmação faz quem já tem convicção aceitar os fatos muito facilmente, por outro lado esses fatos mentirosos e distorcidos aumentam a convicção, porque funcionam como uma espécie de combustível para essa fogueira. E essa convicção se torna mais aprofundada, mais arraigada, de maneira que não se sabe se o fato levou à força da convicção, ou se a força da convicção que fez com que se aceitassem acriticamente os fatos. Então, isso provavelmente é uma espécie de círculo vicioso no qual esses dois fatores se retroalimentam, e é difícil saber exatamente como isso começou.

Essas duas coisas, ao que tudo indica, estão interligadas, embora não saibamos como seria se não houvesse sistema produtor de desinformação. Um pedaço dele, pelo menos, pode ser de ativistas de boa-fé que estão distorcendo informações por confusão, por convicção. E, mesmo que um pedaço grande seja de pessoas maliciosas, que estão mentindo deliberadamente para arregimentar militantes, ainda que tenha isso, não se consegue dizer que seja a causa. Tudo o que conseguimos determinar é que isso está correlacionado com o fenômeno: que a aceitação dessa informação e a crença estão associadas, correlacionadas.

ORGANICOM - A solução do problema é a mudança nas leis ou existe um caminho de auto-organização na sociedade que possa ser referência dos movimentos da esfera pública?

ORTELLADO - A natureza do problema da desinformação política está fundamentalmente ligada a questões políticas. Tem a ver com o problema da polarização da sociedade, porque é a polarização que deixa alguns de seus setores apaixonados demais e muito vulneráveis. São campanhas de desinformação que exploram o viés de confirmação e isso tem a ver com a ascensão do populismo, e as condições sociais e políticas que permitiram esse cenário, que são esses movimentos políticos baseados em retóricas antielitistas. E acho que, claro, as estruturas comunicacionais colaboraram com isso, ao diminuírem as barreiras de participação, ao diminuírem os custos de organização, pois isso permite que grupos políticos emergentes se organizem de maneira mais fácil e que novos atores consigam se expressar. No velho sistema da comunicação de massa isso seria muito difícil pelo controle editorial que é feito pelos proprietários dos meios de comunicação.

Apesar de achar que a natureza do nosso problema é de ordem política, e que precisamos resolver o problema da ascensão do populismo, da descrença das instituições e da polarização política, existem coisas que podem ser feitas do ponto de vista legislativo, do ponto de vista da regulação dos meios de comunicação, da regulação das mídias sociais. Projetos como o chamado PL das Fake News tentam combater isso, em parte. Acredito que deveríamos fazer um projeto muito mais ambicioso, discutindo o processo de moderação das próprias plataformas, que é uma coisa que, cedo ou tarde, terá que ser feita. As plataformas deveriam mudar seus próprios termos de uso, que estimulam processos de desinformação. As leis eleitorais também precisam mudar. Várias medidas paliativas podem ser tomadas para reduzir, minorar, mitigar esses problemas. Mas a solução propriamente dita passa por um aspecto político que diminua o apelo do populismo, que reduza a intensidade da polarização política, e que retome a confiança nas instituições, como o jornalismo, a ciência e o próprio sistema de representação. Sem essas soluções de natureza política, toda a parte legislativa de mudança dos termos de uso das plataformas apenas ameniza o problema. É necessária, mas só ameniza, pois não está indo na natureza, no coração do problema, que é de ordem política. movimento, como a chamada Lei das Fake News (Lei Brasileira de Liberdade, Responsabilidade e Transparência na Internet)? 
ORTELLADO - A natureza do problema regulatório que a gente está enfrentando é que há conflitos entre direitos. E a solução para o conflito de direitos é equilibrá-los. A maneira mais clara, o exemplo mais óbvio, que é a liberdade de expressão, às vezes atropela direitos: podemos falar coisas que são racistas? E fazer comentários que desrespeitem o direito de minorias, falar coisas que atacam a honra? Essas manifestações da expressão precisam ser limitadas, porque atingem direitos de outras pessoas. Se fazemos uma acusação infundada de que uma pessoa é pedófila e assassina, e essa informação começa a circular e gera danos irreparáveis à imagem, à honra e à vida cotidiana dessas pessoas, esse post precisa ser retirado. Nós precisamos fazer um ato de censura, isso precisa ser retirado porque causa dano. Ao fazer isso, você está suprimindo a liberdade de expressão, está equilibrando a liberdade de expressão, que é um direito humano fundamental, com outros direitos, que é o direito que a pessoa tem à sua vida e à sua honra. E os conflitos estão em choque de diversas maneiras.

Por exemplo, agora está em curso uma campanha negacionista da Covid, que minimiza a mortalidade dessa doença, os riscos, a gravidade e a mortalidade. Essa campanha é um atentado à saúde pública porque a sua disseminação faz com que pessoas saiam às ruas, se contaminem e contaminem as pessoas com quem elas convivem, e uma parcela delas, morra. Literalmente. Seria um exagero retórico? Está matando gente. E essa liberdade de expressão precisa ser equilibrada. Esse equilíbrio não necessariamente precisa ser a supressão. Existem várias maneiras de se equilibrar direitos. As plataformas mesmo, antes da supressão, impõem uma gradação da restrição a essa liberdade quando ela conflita com os direitos. 0 conteúdo pode ser rotulado, pode ser acompanhado de uma contestação, pode ter a sua distribuição reduzida, e no limite, ser suprimido.

E encontrar a proporção adequada, de maneira a respeitar a liberdade de expressão, por um lado, e proteger os outros direitos que estão sendo agredidos por essa liberdade de expressão é a arte de uma boa regulação. Esse é um problema delicado que hoje as plataformas estão fazendo sozinhas. Elas decidem seus termos de uso, aplicam à sua maneira, de acordo com 0 interesse e a velocidade privados, o que significa que uma parte disso é feita por robôs e outra por empregados sub-remunerados. As regras, muitas delas, são razoáveis, mas nem sempre feitas de acordo com o interesse público. 0 que acontece hoje são empresas regulando o debate público e político, e isso parece uma situação insustentável. Não faz sentido que uma empresa privada, orientada pelo lucro, crie e organize as regras de moderação do debate público. Isso precisa ser regulado, e a gente precisa de princípios que regulem a moderação de conteúdo, criando essa cadeia, o equilíbrio, a proporcionalidade de uma maneira: segundo regras, segundo princípios públicos, e controlados pelo poder público e não pelo interesse econômico.

\section{ORGANICOM - Esse caminho resolveria a atual insegurança em relação a esse tema? Ea regulação não seria um caminho perigoso?}

ORTELLADO - Essa é a solução de maneira geral. Eu acredito que as empresas até não fizeram um péssimo trabalho, porque elas estão sob enorme escrutínio, enorme pressão do poder político, do público, da imprensa, mas a moderação que elas têm feito não pode ser verificada. Não sabemos se no exercício dessa moderação não estão favorecendo determinado lado no espectro político. Vimos, por exemplo, uma série de matérias na imprensa mostrando, recentemente, que o Facebook sofreu muita pressão do Partido Republicano (EUA). Se o Facebook aplicasse as regras de uma maneira mais ou menos isonômica, a direita seria mais afetada do que a esquerda. E o Partido Republicano não aceitava isso, criando exceções para que as suas regras não impactassem demais a direita. Isso é o poder privado sofrendo pressão do poder político, porque a direita está no governo americano, está no poder nos Estados Unidos nesse momento.

A solução passa por uma regulação, e essa regulação vai precisar equilibrar direitos de uma maneira proporcional, bem cuidada. Isso é arriscado? Isso é extremamente arriscado, mas não é menos arriscado que viver sob o controle de uma corporação privada como acontece hoje. 
ORGANICOM - Vivemos um momento de grande força dos discursos populistas - no Brasil e pelo mundo afora. Como chegamos a esse ponto, que de algum modo é um retorno a estratégias perigosas já praticadas no passado?

ORTELLADO - Eu acho que o populismo - em uma acepção mais técnica - está dando força a esses movimentos que se baseiam em uma retórica antielitista, que buscam representar o povo fugindo da mediação, contornando-a por meio de uma identificação direta com o objetivo de derrubar elites corruptas. 0 populismo nesse conceito mais técnico, mais circunscrito, está fazendo dois tipos de ataques: ao poder político e às instituições, digamos, culturais.

Ao poder político, oferece uma resposta a uma crise de soberania. Quando a gente olha para a literatura, essa é, no meu entender, a melhor linha de respostas. 0 discurso populista vai dizer que as instituições se desenvolveram e "morderam" um pedaço da soberania popular. Há muitas coisas que não podem mais ser legisladas, porque os tribunais constitucionais estabeleceram que são questões constitucionais. Decidem e interpretam a constituição, e "comem" um pedaço da soberania. Juízes não eleitos determinam coisas que os deputados que são eleitos não podem. Com isso, a soberania se reduz. Um pedaço da nossa política monetária, por exemplo, é feita por bancos centrais independentes em vários países. Isso "abocanha" um pedacinho da soberania. Uma parte de regulação é feita por agências independentes, o que absorve uma fatia da soberania. Esta vai ficando enxuta, menos relevante.

Além disso, em paralelo, o que se vê é um enxugamento do orçamento público, porque o sistema de bem estar social foi amadurecendo, ficando cada vez mais oneroso. Então se tem cada vez menos recursos discricionários que permitam fazer políticas sociais que diferenciam a esquerda e a direita. E aí, a esquerda e a direita, como não há orçamento público livre, são muito parecidas. É a crise que se viu lá nos anos 1990, na época do governo Clinton, do novo trabalhismo inglês, do próprio Fernando Henrique Cardoso, na qual esquerda e direita são praticamente indistintas: a esquerda é muito próxima da direita. E quando esquerda e direita ficam muito próximas, o voto não vale nada, porque tanto faz você votar na esquerda ou na direita, se o resultado vai ser um governo com políticas muito semelhantes, ou pouco diferentes. Estavam acontecendo esses processos que reduziam a força da soberania popular. E o populismo, enquanto promessa de renovação profunda por meio de um ataque às instituições dominadas por elites - responde a essa crise de soberania no campo da política.

No campo da cultura está havendo um ataque populista também, antielitista, que diz que essas instituições são elitistas, auto-orientadas e tomadas por ideologias. Essa acusação é delirante e é infundada: a Globo não é comunista, a Folha não é comunista, a USP não é comunista. Porém, esse é um discurso que tem vigor político, que ganha voto, ao qual é necessário que se responda. Existe uma crise nas instituições culturais, que se desconectaram das pessoas. Elas falam uma linguagem própria, têm dinâmicas próprias. Se desconectaram da sociedade e isso fez com que o populismo pudesse apontá-las como elitistas, como distantes do povo e, por isso, corrompidas.

ORGANICOM - E Como reagir a esse processo de desmonte da realidade que usa a ignorância e a crise para fazer o deslocamento da verdade? Qual é o caminho para se restabelecer uma sociedade mais equilibrada e evoluída em seus debates?

ORTELLADO - 0 que se precisa é de reforma dessas instituições. A universidade precisa se reformar e se reconectar com as pessoas. Não pode ser feita somente por gabinetes encastelados em que se usa desnecessariamente uma linguagem difícil. Em alguns casos, é preciso uma linguagem difícil, porque a ciência trata de fenômenos complexos, mas, muitas vezes, se usa desnecessariamente linguagem complexa, não se faz um esforço de divulgação científica, de conexão de pessoas, não se abre as portas das universidades para pessoas comuns. Elas permanecem instituições de difícil acesso. Apenas para 
uma elite, inclusive para uma elite econômica. Enquanto a universidade não se descaracterizar, enquanto mantiver esse processo autocentrado, elitista, desconectado das pessoas, será passível desse ataque populista.

Os meios de comunicação, como as universidades, cada um em sua seara, são responsáveis por estabelecer os fatos sobre os quais o debate público se baseia e contribuíram com essa dinâmica desinformativa, que se "descola" dos fatos. Quando se tem uma sociedade polarizada, que está consumindo o que é produzido por essa máquina de desinformação, pode-se crer que se perdeu a confiança nas instituições que estabelecem os fatos. Esse debate virou uma disputa de narrativas sem referências aos fatos. No velho mundo, o que acontecia é que nós tínhamos fatos científicos, fatos jornalísticos, fatos políticos estabelecidos pelo jornalismo, e havia conflitos interpretativos sobre esses fatos. Havia a visão da direita e visão da esquerda sobre aqueles fatos. Agora, não.

ORGANICOM - Algumas pesquisas indicam que diversas pessoas acreditam pouco nas Instituições em outras lideranças, como as que se servem de discursos populistas, por exemplo. Como enxerga o futuro de nossa sociedade, em especial quando temas de enorme importância são colocados em xeque por leigos contra a opinião de especialistas?

ORTELLADO - Agora nós não concordamos mais sobre os fatos. Em parte, porque nós não cremos nas instituições que estabelecem os fatos, em parte porque a nossa paixão está tão acentuada que a nossa vulnerabilidade está sendo explorada por máquinas de desinformação que tornam nossos discursos um pouco (ou bastante) delirantes. Parte da solução política passa também por reconquistar, por retomar a confiança nas instituições. E para retomar a confiança nas instituições estas precisam se reformar, precisam se tornar menos elitistas, se reconectar. Elas precisam ser mais abertas e mais equilibradas do ponto de vista da política.

A universidade não é comunista, porém ela não tem uma representação equilibrada do conservadorismo. 0 conservadorismo nem tem uma produção intelectual sofisticada, como tem a produção da esquerda, de tão alheio que está a esse universo. É preciso identificar essas forças e incorporar, para tornar a universidade mais plural, mais equilibrada, para atender a todas as correntes da sociedade e para que ela não possa ser questionada pelas forças que a acusam de unilateralismo, de distorção por elites corruptas.

Nem sempre a universidade é, de fato, plural, do ponto de vista político. A mesma coisa acontece com os meios de comunicação. Obviamente, Rede Globo e Folha de São Paulo não são comunistas, mas editorializam a notícia. Muitas vezes não separam a parte editorial da opinião. Muitas vezes, não escutam, não representam, digamos, as partes na construção da notícia de uma maneira equilibrada. Então é preciso se reformar para atender a esse tipo de situação. Os meios de comunicação não são esse monstro controlado por famílias com projetos políticos como é sugerido por alguns. Estão presos a muitas regras jornalísticas, que são muito menos distorcidas do que o discurso populista diz. No entanto, há problemas, inclusive de editorialização das reportagens. É preciso lidar com esses problemas para serem menos suscetíveis a essas críticas.

Universidades e meios de comunicação precisam se reformar, porque faz parte da solução política reconquistar, recriar confiança nas instituições, para que se possa ter fatos comuns e discordar apenas nas interpretações, mas não na existência desse ou daquele fato. Porque daí o discurso se torna sem pontos comuns de apoio, gerando essas dinâmicas de intolerância política, que tendem à violência. E, no limite, só serão resolvidas por meio da violência política, de uma guerra civil, que é para onde se está caminhando caso nada se faça para resolver essa situação. 